\title{
A pilot study identifying a potential plasma biomarker for determining EGFR mutations in exons 19 or 21 in lung cancer patients
}

\author{
ARYO D. PAMUNGKAS ${ }^{1}$, CARL A. MEDRIANO ${ }^{1}$, EUNJUNG SIM ${ }^{2}$, SUNGYONG LEE $^{2}$ and YOUNGJA H. PARK ${ }^{1}$ \\ ${ }^{1}$ College of Pharmacy, Korea University, Jochiwon-eup, Sejong 30029; ${ }^{2}$ Department of Pulmonology, \\ Korea University Guro Hospital, Guro-gu, Seoul 08308, Republic of Korea
}

Received September 8, 2016; Accepted March 13, 2017

DOI: $10.3892 / \mathrm{mmr} .2017 .6530$

\begin{abstract}
The most common type of lung cancer is non-small cell lung cancer (NSCLC), which is frequently characterized by a mutation in the epidermal growth factor receptor (EGFR). Determining the presence of an EGFR mutation in lung cancer is important, as it determines the type of treatment that a patients will receive. Therefore, the aim of the present study was to apply high-resolution metabolomics (HRM) using liquid chromatography-mass spectrometry to identify significant compounds in human plasma samples obtained from South Korean NSCLC patients, as potential biomarkers for providing early detection and diagnosis of minimally-invasive NSCLC. The metabolic differences between lung cancer patients without EGFR mutations were compared with patients harboring EGFR mutations. Univariate analysis was performed, with a false discovery rate of $\mathrm{q}=0.05$, in order to identify significant metabolites between the two groups. In addition, hierarchical clustering analysis was performed to discriminate between the metabolic profiles of the two groups. Furthermore, the significant metabolites were identified and mapped using Mummichog software, in order to generate a potential metabolic network model. Using metabolome-wide association studies, metabolic alterations were identified. Linoleic acid [303.23 m/z, $\left.(\mathrm{M}+\mathrm{Na})^{+}\right], 5$-methyl tetrahydrofolate $\left[231.10 \mathrm{~m} / \mathrm{z},(\mathrm{M}+2 \mathrm{H})^{+}\right]$and $\mathrm{N}$-succinyl-L-glutamate-5
\end{abstract}

Correspondence to: Dr Youngja H. Park, College of Pharmacy, Korea University, 2511 Sejong-ro, Jochiwon-eup, Sejong 30029, Republic of Korea

E-mail: yjhwang@korea.ac.kr

Abbreviations: HRM, high-resolution metabolomics; EGFR, epidermal growth factor receptor; 5-MTHF, 5-methyltetrahydro folate

Key words: lung cancer, liquid chromatography-mass spectrometry, high-resolution metabolomics, epidermal growth factor receptor mutation, biomarker semialdehyde $\left[254.06 \mathrm{~m} / \mathrm{z},(\mathrm{M}+\mathrm{Na})^{+}\right]$, were observed to be elevated in patients harboring EGFR mutations, whereas tetradecanoyl carnitine $\left[394.29 \mathrm{~m} / \mathrm{z},(\mathrm{M}+\mathrm{Na})^{+}\right]$was observed to be reduced. This suggests that these compounds may be affected by the EGFR mutation. In conclusion, the present study identified four potential biomarkers in patients with EGFR mutations, using HRM combined with pathway analysis. These results may facilitate the development of novel diagnostic tools for EGFR mutation detection in patients with lung cancer.

\section{Introduction}

In South Korea, lung cancer is expected to contribute to 17,505 male mortalities in the year 2016 which is the highest number among all cancers (1). The increasing mortality rates in patients with lung cancer, has led to an increase in the number of studies investigating this malignancy. There are two major types of lung cancer; one of which is small-cell lung cancer, which is clinically aggressive and often already advanced at diagnosis. The remaining type is non-small cell lung cancer (NSCLC), which is the most common type of lung cancer, and is known to exhibit various pathological features $(2,3)$. The major criteria that distinguishes these forms are based on their histological characteristics, such as cell size and the nuclear/cytoplasmic ratio (4). Adenocarcinoma and squamous cell carcinoma are the dominant phenotypes of NSCLC. Squamous cell carcinoma is strongly associated with smoking and chronic inflammation (5).

The epidermal growth factor receptor (EGFR) is located on the cell surface and functions as a major contributor in signal transduction pathways that control cell proliferation, survival and differentation (6). Mutations in this tyrosine-kinase receptor may induce an autophosphorylation process, leading to the continuous promotion of cellular proliferation, decreasing apoptosis and in the end, malignant transformation occurred $(7,8)$. In East Asia, the EFGR mutation occurs in approximately $35 \%$ of patients with lung cancer (9). The mutation frequently occurs in exon 18-21, which is the first exon that encodes the tyrosine-kinase domain. The two most common mutations are a deletion in exon 19 and point mutation in exon 21 (10-12). Determining the type of mutation is important, as it is used to determine patient treatment. A 
previous study demonstrated that the presence of an EGFR mutation is associated with enhanced progression-free survival and a high response rate to EGFR tyrosine kinase inhibitors (TKIs), when compared with standard first-line chemotherapy in NSCLC (13). In addition, different mutations may be associated with different clinical characteristics. As determined by Fukuoka et al (13), NSCLCs in Chinese patients harboring mutations in exon 21 of EGFR exhibit a greater number of malignant features when compared with NSCLCs in patients harboring mutations in exon 19. Therefore, determining the type of mutation early during diagnosis is essential.

The detection of EGFR mutations is typically achieved using invasive cytologic or histologic techniques, followed by DNA-sequencing (14-16). However, a less invasive technique, such as the collection of blood samples, is important for aiding diagnosis, as cytologic or histologic detection is time-consuming and unsafe (17). Biomarkers, which are measurable compounds present in biological fluids, may be used for diagnosis, assessing disease outcome and progression, and for predicting outcomes of treatment in clinical practice (18-21).

In a previous study, the use of high-resolution metabolomics (HRM) generated promising results by identifying prospective biomarkers that effectively discriminated between healthy subjects and patients with lung cancer $(20,22,23)$. In the present study, HRM was performed using a recently developed configuration involving liquid chromatography coupled with mass spectrometry (LC-MS/MS). Quadrupole time-of-flight (Q-TOF) MS was employed to investigate and identify significant compounds as potential biomarkers in human plasma samples from South Korean patients with lung cancer. The aim of the present study was to identify biomarkers associated with mutations in exon 19 or 21 of EGFR, in order to facilitate the early detection and provide a minimally-invasive diagnosis of NSCLC.

\section{Materials and methods}

Sample collection. A total of 15 plasma samples were obtained from patients with NSCLC lung cancer (age, 55-87; male/female, 7/8) admitted to Korea University Guro Hospital (Seoul, Republic of Korea) between January 2014 and September 2014. Of the 15 samples, 5 samples were derived from patients without EGFR mutations (termed NoEM), 4 samples were derived from patients harboring EGFR mutations in exon 19 and 6 samples were derived from patients harboring EGFR mutations in exon 21. Subjects with mutations in exons 19 or 21 were termed EMLC and were diagnosed based on PNA-mediated real-time polymerase chain reaction clamping using the PNAClamp ${ }^{\mathrm{TM}}$ EGFR Mutation Detection kit (Panagene, Inc., Daejeon, Republic of Korea). Details, such as sex and body mass index (BMI) are provided in Table I. The BMI values were analyzed using a Student's t-test, which demonstrated no significant differences among the NoEM and EMLC groups. EMLC subjects received EGFR TKI treatments while NoEM subjects received supportive care. The present study was approved by the Institutional Review Board of Korea University (approval no. KUGH14273-002), and written informed consent was obtained from all patients.
Table I. Age, sex, weight and BMI of patients with lung cancer included in the present study.

\begin{tabular}{lcc}
\hline Parameters & No EGFR mutation & EGFR mutation \\
\hline Number of subjects & 5 & $10(4 / 6)$ \\
Age (years) & $77.6 \pm 8.65$ & $65.4 \pm 10.85$ \\
Sex (male/female) & $3 / 2$ & $4 / 6$ \\
Weight $(\mathrm{kg})$ & $60.17 \pm 10.38$ & $52.26 \pm 9.40$ \\
BMI $\left(\mathrm{kg} / \mathrm{m}^{2}\right)$ & $25.61 \pm 2.36$ & $22.32 \pm 3.61$ \\
Stage of disease & T2aN0M0; & T2aN2M0; \\
& T1aN0M1b; & T2aN2M1b; \\
& T2aN2M1b; & T3N1M0; \\
& T2N3M1b; & T2aN0M0; \\
& T2aN2M1a; & T2N3M1b; \\
& & T2aN0M0; \\
& & T2N0M1b; \\
& & T2N0M1b; \\
& & T4N2M1a; \\
& & No information \\
& & for 1 subject
\end{tabular}

Values are expressed as mean \pm standard deviation. BMI, body mass index; EGFR, epidermal growth factor receptor.

Sample preparation and LC-MS measurements. Samples $(50 \mu 1)$ were treated with acetonitrile $(1: 2, \mathrm{v} / \mathrm{v})$, and centrifuged at $14,000 \times \mathrm{g}$ for $5 \mathrm{~min}$ at $4^{\circ} \mathrm{C}$ in order to separate proteins (24). Metabolites were separated using the Agilent 1200 High Performance Liquid Chromatography (HPLC) System (Agilent Technologies, Inc., Santa Clara, CA, USA) with a Higgins Analytical Targa HPLC C18 100x2.1 mm column, $5 \mu \mathrm{m}$ particle size (Higgins Analytical, Inc., Mountain View, CA, USA). Mobile phase A consisted of $0.1 \%$ formic acid in water (HPLC grade, Tedia Company, Inc., Fairfield, Ohio, USA) and mobile phase B consisted of $0.1 \%$ formic acid in acetonitrile (HPLC grade, Tedia Company, Inc.). The HPLC gradient was programed as follows: $0-7 \mathrm{~min}, 5 \%$ for $\mathrm{B}$; $7-15 \mathrm{~min}$, gradient decrease to $2 \%$ for B; $15-20 \mathrm{~min}$, hold $40 \%$ for $\mathrm{B} ; 20-24 \mathrm{~min}, 95 \%$ for $\mathrm{B}$; $24-25 \mathrm{~min}$, gradient decrease to $2 \%$ for $\mathrm{B}$. The injection volume was $5 \mu \mathrm{l}$, with a flow rate of $0.4 \mathrm{ml} / \mathrm{min}$ and a column temperature of $40^{\circ} \mathrm{C}$. Masses of metabolites ranging from $50-1000 \mathrm{~m} / \mathrm{z}$ were detected using the Agilent 6530 Accurate Mass Q-TOF-LC/MS (Agilent Technologies, Inc.) in the positive ionization mode (25). This LC-MS/MS is ideally suited for metabolic stability and profiling studies, as this system is highly sensitive for the detection of compounds at low concentrations $(\mathrm{pg} / \mathrm{ml})$, has a resolving power of $40 \mathrm{k}$, and is able to identify masses and isotopes for the accurate identification of metabolites. This system was used to detect the $\mathrm{m} / \mathrm{z}$ of ions from 50 to 1,000, with 20,000 resolution (arbitrary units) over $30 \mathrm{~min}$, and LC operated with data extraction using the apLCMS software version 5.9.6 (http://clinicalmetabolomics.org/welcome/default/software) (26), which provided a minimum of 3,000 reproducible features; a number of which displayed sufficient mass accuracy to allow prediction of 
A

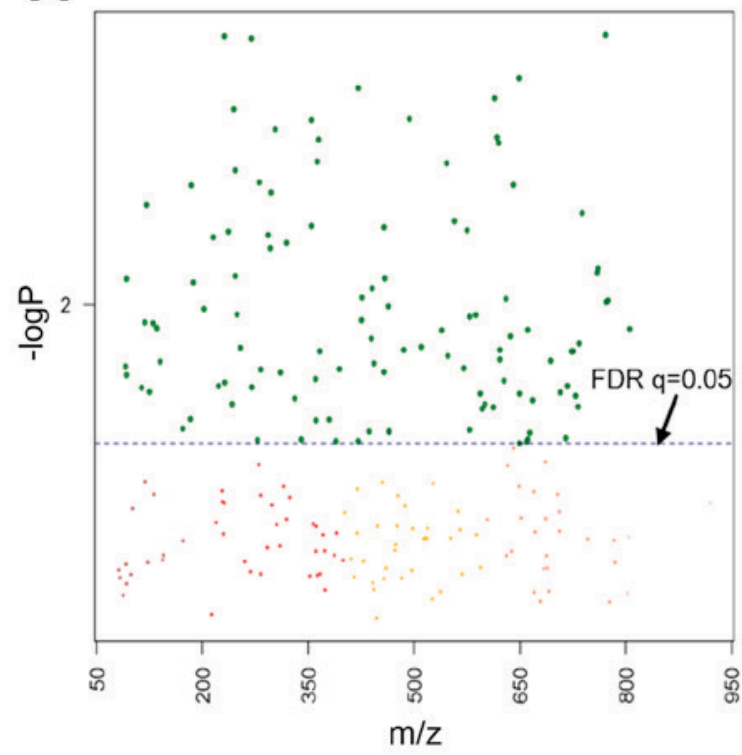

B

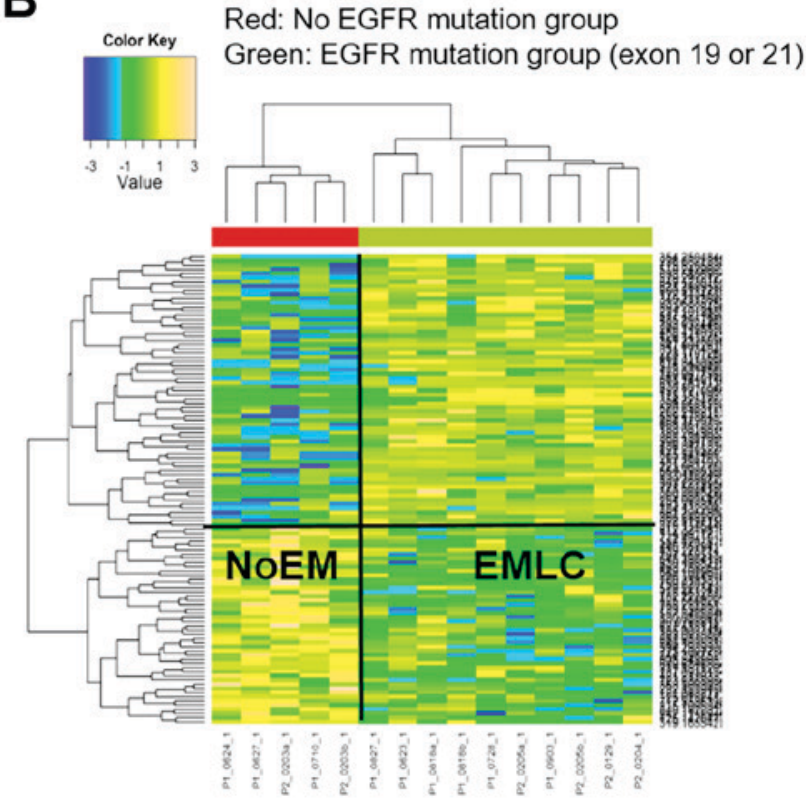

Figure 1. Metabolome-wide association study. (A) Manhattan plot and (B) two-way hierarchical cluster analysis using significant FDR features separated into two groups. The red cluster represents the NoEM group and the green cluster represents the EMLC group. The dotted line in the Manhattan plot represents the FDR where $q=0.05$, and metabolites above this line depict the significant metabolites $(n=112)$ between two groups. The metabolite clusters are shown on the the left side of HCA heatmap. FDR, false discovery rate; NoEM, group of patients with no EGFR mutation; EMLC, group of patients harboring a mutation in exon 19 or 21 of the EGFR gene.

elemental composition. Ion intensity, $\mathrm{m} / \mathrm{z}$, and retention time was used to define an $\mathrm{m} / \mathrm{z}$ feature.

Metabolic profiling with univariate and multivariate statistical analysis. apLCMS generated the total features from the samples for subsequent statistical analyses and bioinformatics. Features from triplicate LC-MS analyses were averaged, $\log _{2}$ transformed and normalized by z-transformation. Univariate analysis and the false discovery rates (FDR) (27) were calculated to reduce the incidence of false positives, and Manhattan plots were constructed using the Limma R package (version, 2.15; https://www.r-project.org/) (28), in order to identify the significantly different metabolites between NoEM and EMLC groups. Using the same package, two-way hierarchical cluster analysis (HCA) was used to separate the metabolic profiles of the two groups based on their metabolite profiles (29). The Limma package is used for the analysis of gene expression data generated from microarray or RNA-Sequencing technologies. It provides the ability to compare a number of targets simultaneously $(21,30)$. Receiver operating characteristic (ROC) curves (MedCalc Software bvba version 16.8, Ostend Belgium) were used to classify the samples based on significant metabolite levels.

Data annotation and pathway analysis. Using the list of all $\mathrm{m} / \mathrm{z}$ features detected $\left(L_{r e f}\right)$ and the significant $\mathrm{m} / \mathrm{z}$ features $\left(L_{\text {sig }}\right)$, the significant metabolites were annotated using Mummichog software version 1.0 .5 (http://clinicalmetabolomics. org/welcome/default/software) to generate a potential metabolic network model (31). Mummichog software was used to identify potentially matched metabolites from the $\mathrm{m} / \mathrm{z}$ features in $L_{\text {sig }}$, as well as establish a reference metabolic network for all modules that may be produced by these metabolites. Random lists of $\mathrm{m} / \mathrm{z}$ features were generated from $L_{\text {ref }}$ a number of times to estimate the null distribution of module activities, in order to compute its statistical significance. A module may be within a known pathway or in between several pathways. The predicted metabolites listed in modules were colored according to fold change. This program has been successfully used to facilitate the identification of metabolite activity networks in immune responses to viruses (31), and for the metabolic profiling of fruit flies (32). Based on the results from Manhattan plot, FDR, HCA, and Mummichog pathway analysis, potential biomarkers were then selected and a histogram displaying differences in the relative concentration of different metabolites in NoEM and EMLC groups were generated using Microsoft Excel (Microsoft Corporation, Redmond, WA, USA).

Statistical analysis. Differences in the levels of endogenous compounds between NoEM and EMLC groups were analyzed using the Student's t-test followed by FDR multiple testing correction. Statistical analysis was performed using the Limma $\mathrm{R}$ package version 2.15 version (https://www.r-project.org/). $\mathrm{P}<0.05$ was considered to indicate a statistically significant difference. To reduce the incidence of false positives, P-values were adjusted by applying a multiple testing correction (the Benjamini and Hochberg procedure for adjusting the false discovery rate), thus producing optimum statistical significance.

\section{Results}

In the present study, metabolome-wide association analysis was performed to determine metabolic alterations in NoEM and EMLC groups of patients with lung cancer. Statistical tests were performed using the Manhattan plot to identify significant features between the NoEM vs. EMLC groups. As 
A

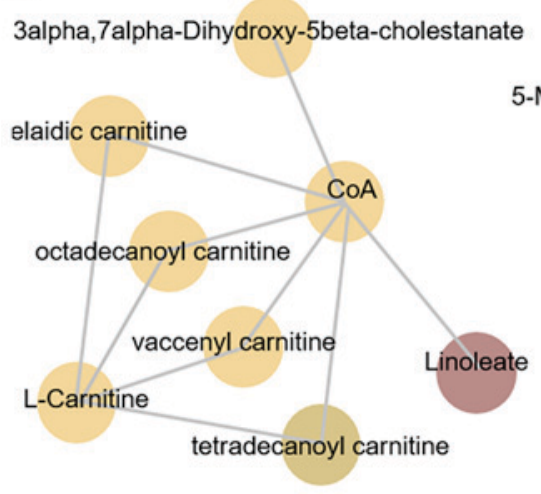

B

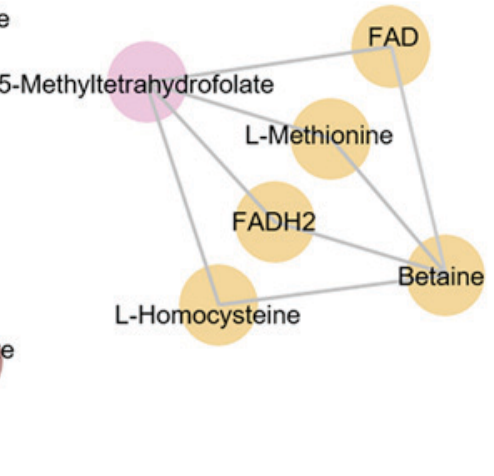

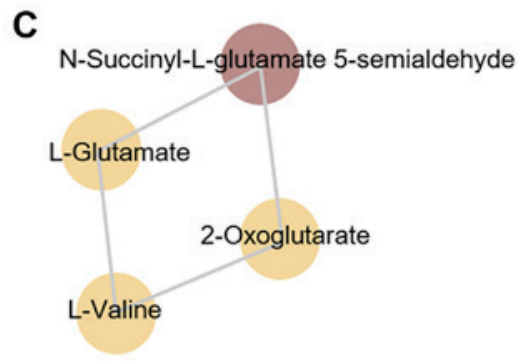

Figure 2. Mummichog analysis was used to generate metabolic networks that were affected patients with lung cancer that harbored a mutation in exons 19 or 21 of the epidermal growth factor receptor. The (A) carnitine shuttle, (B) folate and (C) amino acid metabolism pathways were identified. CoA, coenzyme A; FAD, flavin adenine dinucleotide; FADH2, 1,5-dihyro-FAD.

Table II. ROC curves for the significant metabolites identified.

\begin{tabular}{lccccc}
\hline Metabolite & AUC & Sensitivity (\%) & Specificity (\%) & $\begin{array}{c}\text { Positive predictive } \\
\text { value (\%) }\end{array}$ & $\begin{array}{c}\text { Negative predictive } \\
\text { value }(\%)\end{array}$ \\
\hline Linoleate & 0.68 & 46.67 & 86.67 & 87.5 & 44.8 \\
5-MTHF & 0.72 & 43.33 & 100.00 & 100.0 & 46.9 \\
NSGS & 0.65 & 46.67 & 86.67 & 87.5 & 44.8 \\
Tetradecanoyl carnitine & 0.69 & 63.33 & 73.33 & 82.6 & 50.0 \\
\hline
\end{tabular}

ROC, receiver operating characteristic; AUC, area under curve; 5-MTHF, 5-methyltetrahydrofolate; NSGS, N-succinyl-L-glutamate-5 semialdehyde.

shown in Fig. 1A, the y-axis represents the $-\log 10$ of the raw P-values between the NoEM and EMLC groups, while the $\mathrm{X}$-axis represents the $\mathrm{m} / \mathrm{z}$ values ranging from 50 to 1,000 . The dashed-line represents the significant FDR threshold $(q=0.05)$, which distinguishes the significant features from insignificant $\mathrm{m} / \mathrm{z}$ values. Therefore, metabolites were considered to be significantly different in the EMLC and NoEM groups if they were placed above this threshold.

The number of features that were significantly different between the EMLC and NoEM groups was 112 out of the 3,939 total detected features (Fig. 1A). Two-way HCA was performed to identify the correlation between samples and significant metabolites, with a clear separation of NoEM and EMLC groups expected. As demonstrated in Fig. 1B, the NoEM group (red panel), is grouped as one cluster while the EGFR group (green panel) is grouped as a different cluster. This apparent separation in the heatmaps suggests that the metabolites are highly differentiated in each group.
Mummichog analysis. Metabolite enrichment was achieved using the Mummichog program. This program is used to generate metabolite networks and associated particular pathways for display as interactive figures, with color-identified nodules based on fold changes. Among the metabolites that were significantly different between the NoEM and EMLC groups, four groups of significant metabolites that demonstrated a strong correlation to certain pathways were identified. The first group consisted of metabolites associated with fatty acid (FA) metabolism and the carnitine shuttle, which are pathways that are associated with energy production. As shown in Fig. 2A, linoleic acid and tetradecanoyl carnitine were observed to be the significant metabolites, as indicated by the different colored modules when compared with the other metabolites. The remaining groups correlated with the following signaling pathways: Urea cycle/amino group metabolism, amino acids and folate metabolism. As demonstrated in Fig. 2B and C, 5-methyltetrahydrofolate (5-MTHF) 
A Linoleate, $\mathrm{m} / \mathrm{z} 303.228$,

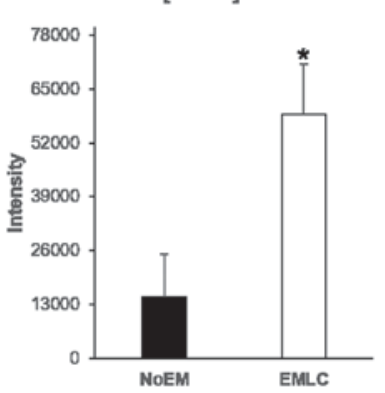

B Tetradecanoyl carnitine, $\mathrm{m} / \mathrm{z} 394.294,[\mathrm{M}+\mathrm{Na}]^{+}$

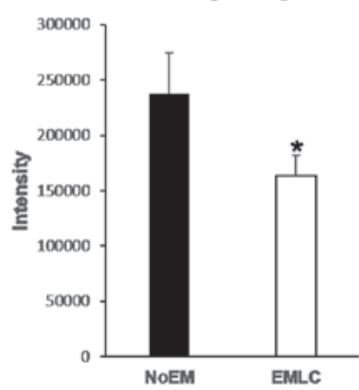

C 5-MTHF, m/z 231.101,

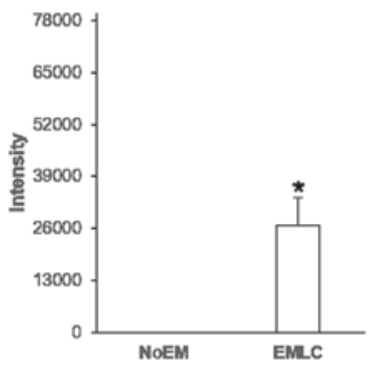

D N-Succinyl-L-glutamate 5semialdehyde, $\mathrm{m} / \mathrm{z} 254.06$, $[\mathrm{M}+\mathrm{Na}]^{+}$

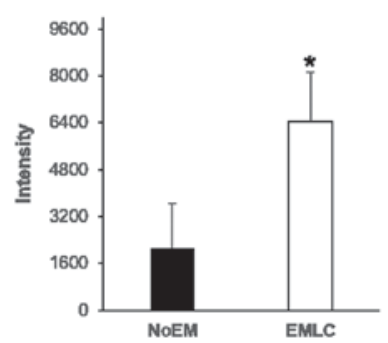

Figure 3. Abundance of identified metabolites in NoEM and EMLC groups. The relative concentration of (A) linoleate, (B) tetradecanoyl carnitine, (C) 5-MTHF, and (D) N-succinyl-L-glutamate-5 semialdehyde in NoEM and EMLC groups. Data are expressed as mean \pm standard deviation. ${ }^{*} \mathrm{P}<0.05$ vs. NoEM group. NoEM, group of patients with no EGFR mutation; EMLC, group of patients harboring a mutation in exon 19 or 21 of the EGFR gene; EGFR, epidermal growth factor receptor; 5-MTHF, 5-methyltetrahydrofolate.

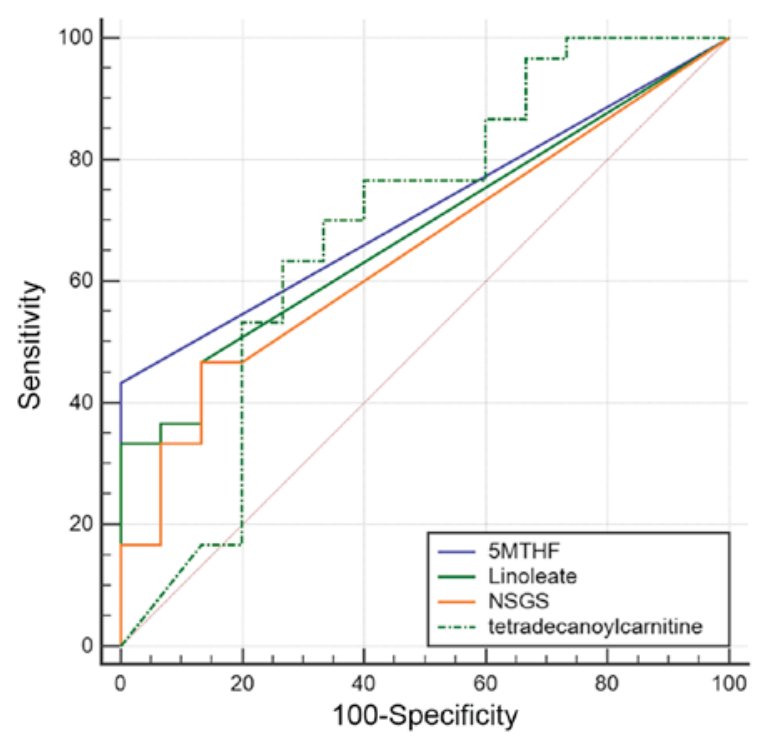

Figure 4. Classification of subjects according to the level of significant compounds identified. ROC curve analysis demonstrated that the level of linoleate, 5-MTHF, NSGS, and tetradecanoyl carnitine was able to differentiate the EMLC group from the NoEM group. ROC, receiver operating characteristic; 5-MTHF, 5-methyltetrahydrofolate; NSGS, N-succinyl-L-glutamate-5 semialdehyde; EMLC, group of patients harboring a mutation in exon 19 or 21 of the EGFR gene; NoEM, group of patients with no EGFR mutation.

and N-succinyl-L-glutamate-5 semialdehyde (NSGS) were significantly different among the metabolites.

Identification and verification of potential biomarkers. Differences in the levels of endogenous compounds were identified between NoEM and EMLC groups. Linoleic acid $\left[303.23 \mathrm{~m} / \mathrm{z},(\mathrm{M}+\mathrm{Na})^{+}\right], 5$-methyl tetrahydrofolate $[231.10 \mathrm{~m} / \mathrm{z}$, $\left.(\mathrm{M}+2 \mathrm{H})^{+}\right]$and $\mathrm{N}$-succinyl-L-glutamate-5 semialdehyde $\left[254.06 \mathrm{~m} / \mathrm{z},(\mathrm{M}+\mathrm{Na})^{+}\right]$were observed to be significantly elevated in patients harboring EGFR mutations, whereas tetradecanoyl carnitine $\left[394.29 \mathrm{~m} / \mathrm{z},(\mathrm{M}+\mathrm{Na})^{+}\right]$was observed to be significantly reduced (Fig. 3). ROC analysis was then performed to assess the classification of samples based on the detected levels of significant compounds (Fig. 4). The area under the curve (AUC) for linoleate, 5-MTHF, NSGS and tetradecanoyl carnitine, was $0.68,0.72,0.65$, and 0.69 , respectively (Table II). The AUC values of two compounds with the highest values were verified by detecting the transition of the specific precursor ion to the product ion: $394.29-377.26 \mathrm{~m} / \mathrm{z}$ for tetradecanoyl carnitine and 231.1-170.7 m/z for 5-MTHF (data not shown).

\section{Discussion}

The main objective of the present study was to identify low molecular-weight metabolites that may be used as biomarkers for lung cancer mutation diagnostic tools. By comparing the metabolite profiles of plasma samples from patients with no EGFR mutations with patients harboring EGFR mutations, four compounds, including linoleic acid, tetradecanoyl carnitine, 5-MTHF, and NSGS, were identified as potential biomarkers.

Activating mutations in EGFR is a major factor that contributes to abnormal cell proliferation and malignant transformation (33). Gene mutations in cancer cells may lead to uncontrolled proliferation and disruption of signaling pathways, which activates the uptake and metabolism of nutrients. Therefore, mutations promote cell survival and increase cell growth $(34,35)$.

Human cells generate energy by utilizing glucose and lipid metabolic pathways, which are affected by the irregularities in cancer cells. First described by Warburg, glucose metabolism alterations in cancer cells have been investigated in a number of studies (36-38). In addition, alterations in FA metabolism in cancer cells have recently garnered increasing attention (39-41). FAs, such as linoleic acid, are metabolized via mitochondrial FA oxidation. FA is first activated via coenzyme A (CoA) esterification, and is subsequently transported to the mitochondria by the carnitine shuttle (42). This shuttle transfers long-chain acyl-CoAs as their corresponding carnitine ester, which are then converted to the FA-acylCoA form prior to $\beta$-oxidation for energy production. This transfiguration process demonstrates the importance of the carnitine shuttle in FA-dependent energy formation.

Previous studies have suggested that peroxisome proliferator-activated receptor (PPAR) serves a vital role as a regulator of FA oxidation and carnitine metabolism (43-45). The PPAR $\gamma$ subtype contributes to the suppression of cell proliferation $(45,46)$. According to Hou et al $(46)$ dysregulated EGFR expression promotes cell proliferation by inhibiting PPAR $\gamma$ function. Hence, mutations in EGFR potentially disrupt the function of PPAR in regulating FA metabolism.

In the current study, the activity of the carnitine shuttle was highlighted as a putative deregulated pathway in patients with EGFR mutations. Based on the results of previous studies, it is 
possible that EGFR mutations led to deregulation of the carnitine shuttle by terminating PPAR function. Four acyl carnitines were detected, notably tetradecanoyl carnitine, which was present at lower levels in EMLC patients, while linoleic acid, a long-chain FA, was observed to be elevated. The levels of linoleic acid may have been elevated due to disruption of its transport mechanism to the mitochondria. In addition, regardless of its role in the cytosol, acyl carnitine is transported across cell membranes and can therefore be detected in plasma (47).

In the present study, the metabolism of amino acids and folate was identified as an affected pathway in patients with lung cancer harboring EGFR mutations. Previous studies have identified abnormalities in metabolic proteins in lung cancer patients by determining the difference in amino acid levels in blood plasma samples $(48,49)$. The level of plasma amino acids may indicate the sum of various pathologic conditions affecting the total flux of amino acids in the body (50). In the present study, the detection of NSGS was significantly higher in the EMLC group of patients when compared with the NoEM group. This compound is an intermediate in the glutamate, aspartate and proline metabolic pathways. The elevated levels of 5-MTHF observed in the EMLC group may have been associated with overexpression of folate receptor $\alpha(\mathrm{FR} \alpha)$ due to the EGFR mutation (51). FR $\alpha$ is a glycoprotein located in the cell membrane that binds folic acid with a high affinity $\left(\mathrm{K}_{\mathrm{d}}<1 \mathrm{nM}\right)$ and mediates its intracellular transport $(52,53)$. In addition, FR $\alpha$ binds one-carbon reduced folate derivatives, such as 5-MTHF, with a lower affinity $\left(K_{d}, 1-10 \mathrm{nM}\right)(53,54)$. Therefore, overexpression of $\mathrm{FR} \alpha$, and the subsequent binding of folic acid, may have been caused by the observed increase in extracellular 5-MTHF. Notably, this study demonstrated extreme differences in the abundance of 5-MTHF between NoEM and EMLC groups. In addition, the medication history of all patients was checked to remove bias. Three subjects, one of them from the NoEM group, received folic acid supplements; however, this did not influence the results, as zero abundance of 5-MTHF was detected in the NoEM group. This may be useful for developing improved treatments for patients with NSCLC, as elevated 5-MTHF levels may be associated with high levels of FR $\alpha$ expression, which may improve responses to antifolate chemotherapy (51). In addition, the results of a phase II clinical trial in China demonstrated that the efficacy of TKIs (erlotinib) combined with antifolate (capecitabine) treatment were significantly beneficial in patients with lung cancer with EGFR mutations who hadn't received cancer treatment prior to the study (55).

In conclusion, four potential biomarkers were identified in the plasma samples of patients with lung cancer that harbor EGFR mutations. Two of these biomarkers were associated with energy production signaling pathways, specifically FA metabolism. These results may provide opportunities for the development of novel diagnostic tools for EGFR mutation detection in lung cancer. Future studies with a larger population of subjects are required to validate the results, and provide a rationale for the clinical practicality of this approach.

\section{Acknowledgements}

The present study was supported by the National Research Foundation of Korea (grant nos. NRF-2014R1A1A2053787 and NRF-2017R1A2B4003890) and the Korea Health Industry Development Institute (grant no. HI14C2686). The authors would like to thank Dr Karan Uppal from the Emory University School of Medicine (Atlanta, GA, USA) for providing the R-package used to run the metabolome-wide association study. Mr. Aryo D. Pamungkas gratefully acknowledges the Indonesia Endowment Fund for Education (LPDP) for the financial support of his master degree scholarship.

\section{References}

1. Jung KW, Won YJ, Oh CM, Kong HJ, Cho H, Lee JK, Lee DH and Lee KH: Prediction of cancer incidence and mortality in Korea, 2016. Cancer Res Treat 48: 451-457, 2016.

2. Collins LG, Haines C, Perkel R and Enck RE: Lung cancer: Diagnosis and management. Am Fam Physician 75: 56-63, 2007.

3. Chen Z, Fillmore CM, Hammerman PS, Kim CF and Wong KK: Non-small-cell lung cancers: A heterogeneous set of diseases. Nat Rev Cancer 14: 535-546, 2014.

4. Travis WD: Update on small cell carcinoma and its differentiation from squamous cell carcinoma and other non-small cell carcinomas. Modern Pathol 25: S18-S30, 2012.

5. Langer CJ, Besse B, Gualberto A, Brambilla E and Soria JC: The evolving role of histology in the management of advanced non-small-cell lung cancer. J Clin Oncol 28: 5311-5320, 2010.

6. Wieduwilt MJ and Moasser MM: The epidermal growth factor receptor family: Biology driving targeted therapeutics. Cell Mol Life Sci 65: 1566-1584, 2008.

7. Scagliotti GV, Selvaggi G, Novello $S$ and Hirsch FR: The biology of epidermal growth factor receptor in lung cancer. Clin Cancer Res 10: 4227s-4232s, 2004.

8. da Cunha Santos G, Shepherd FA and Tsao MS: EGFR mutations and lung cancer. Annu Rev Pathol 6: 49-69, 2011.

9. Paez JG, Janne PA, Lee JC, Tracy S, Greulich H, Gabriel S, Herman P, Kaye FJ, Lindeman N, Boggon TJ, et al: EGFR mutations in lung cancer: Correlation with clinical response to gefitinib therapy. Science 304: 1497-1500, 2004.

10. Yamamoto H, Toyooka $S$ and Mitsudomi T: Impact of EGFR mutation analysis in non-small cell lung cancer. Lung Cancer 63: 315-321, 2009.

11. Shigematsu H and Gazdar AF: Somatic mutations of epidermal growth factor receptor signaling pathway in lung cancers. Int $\mathbf{J}$ Cancer 118: 257-262, 2006.

12. Siegelin MD and Borczuk AC: Epidermal growth factor receptor mutations in lung adenocarcinoma. Lab Invest 94: 129-137, 2014.

13. Fukuoka M, Wu YL, Thongprasert S, Sunpaweravong P, Leong SS, Sriuranpong V, Chao TY, Nakagawa K, Chu DT, Saijo N, et al: Biomarker analyses and final overall survival results from a phase III, randomized, open-label, first-line study of gefitinib versus carboplatin/paclitaxel in clinically selected patients with advanced non-small-cell lung cancer in Asia (IPASS). J Clin Oncol 29: 2866-2874, 2011.

14. Metzger B, Chambeau L, Begon DY, Faber C, Kayser J, Berchem G, Pauly M, Boniver J, Delvenne P, Dicato M and Wenner T: The human epidermal growth factor receptor (EGFR) gene in European patients with advanced colorectal cancer harbors infrequent mutations in its tyrosine kinase domain. BMC Med Genet 12: 144, 2011.

15. Khoo C, Rogers TM, Fellowes A, Bell A and Fox S: Molecular methods for somatic mutation testing in lung adenocarcinoma: EGFR and beyond. Transl Lung Cancer Res 4: 126-141, 2015.

16. Jung CY: Biopsy and mutation detection strategies in non-small cell lung cancer. Tuberc Respir Dis (Seoul) 75: 181-187, 2013.

17. Lindeman NI, Cagle PT, Beasley MB, Chitale DA, Dacic S, Giaccone G, Jenkins RB, Kwiatkowski DJ, Saldivar JS, Squire J, et al: Molecular testing guideline for selection of lung cancer patients for EGFR and ALK tyrosine kinase inhibitors: Guideline from the College of American Pathologists, International Association for the Study of Lung Cancer, and Association for Molecular Pathology. J Thorac Oncol 8: 823-859, 2013.

18. Hulka BS and Wilcosky T: Biological markers in epidemiologic research. Arch Environ Health 43: 83-89, 1988.

19. Mayeux R: Biomarkers: Potential uses and limitations. NeuroRx 1: 182-188, 2004. 
20. Miyamoto S, Taylor SL, Barupal DK, Taguchi A, Wohlgemuth G Wikoff WR, Yoneda KY, Gandara DR, Hanash SM, Kim K and Fiehn O: Systemic metabolomic changes in blood samples of lung cancer patients identified by gas chromatography time-of-flight mass spectrometry. Metabolites 5: 192-210, 2015.

21. Park YH, Shi YP, Liang B, Medriano CA, Jeon YH, Torres E, Uppal K, Slutsker L and Jones DP: High-resolution metabolomics to discover potential parasite-specific biomarkers in a Plasmodium falciparum erythrocytic stage culture system. Malar J 14: 122, 2015.

22. Peralbo-Molina A, Calderón-Santiago M, Priego-Capote F, Jurado-Gámez B and Luque de Castro MD: Metabolomics analysis of exhaled breath condensate for discrimination between lung cancer patients and risk factor individuals. J Breath Res 10: 016011, 2016.

23. Pamungkas AD, Park C, Lee S, Jee SH and Park YH: High resolution metabolomics to discriminate compounds in serum of male lung cancer patients in South Korea. Respir Res 17: 100, 2016.

24. Johnson JM, Yu T, Strobel FH and Jones DP: A practical approach to detect unique metabolic patterns for personalized medicine. Analyst 135: 2864-2870, 2010.

25. De Sotto R, Medriano C, Cho Y, Seok KS, Park Y and Kim S: Significance of metabolite extraction method for evaluating sulfamethazine toxicity in adult zebrafish using metabolomics. Ecotoxicol Environ Saf 127: 127-134, 2016.

26. Yu T, Park Y, Johnson JM and Jones DP: apLCMS-adaptive processing of high-resolution LC/MS data. Bioinformatics 25 1930-1936, 2009.

27. Benjamini Y, Drai D, Elmer G, Kafkafi N and Golani I: Controlling the false discovery rate in behavior genetics research. Behav Brain Res 125: 279-284, 2001.

28. Cribbs SK, Park Y, Guidot DM, Martin GS, Brown LA, Lennox J and Jones DP: Metabolomics of bronchoalveolar lavage differentiate healthy HIV-1-infected subjects from controls. Aids Res Hum Retroviruses 30: 579-585, 2014.

29. Uppal K, Soltow QA, Strobel FH, Pittard WS, Gernert KM, Yu T and Jones DP: xMSanalyzer: Automated pipeline for improved feature detection and downstream analysis of large-scale, non-targeted metabolomics data. BMC Bioinformatics 14: 15, 2013.

30. Neujahr DC, Uppal K, Force SD, Fernandez F, Lawrence C, Pickens A, Bag R, Lockard C, Kirk AD, Tran V, et al: Bile acid aspiration associated with lung chemical profile linked to other biomarkers of injury after lung transplantation. Am J Transplant 14: 841-848, 2014.

31. Li S, Park Y, Duraisingham S, Strobel FH, Khan N, Soltow QA, Jones DP and Pulendran B: Predicting network activity from high throughput metabolomics. PLoS Comput Biol 9: e1003123, 2013.

32. Hoffman JM, Soltow QA, Li S, Sidik A, Jones DP and Promislow DE: Effects of age, sex, and genotype on high-sensitivity metabolomic profiles in the fruit fly, Drosophila melanogaster. Aging Cell 13: 596-604, 2014

33. Kim YT, Kim TY, Lee DS, Park SJ, Park JY, Seo SJ, Choi HS, Kang HJ, Hahn S, Kang CH, et al: Molecular changes of epidermal growth factor receptor (EGFR) and KRAS and their impact on the clinical outcomes in surgically resected adenocarcinoma of the lung. Lung Cancer 59: 111-118, 2008.

34. Hsu PP and Sabatini DM: Cancer cell metabolism: Warburg and beyond. Cell 134: 703-707, 2008

35. DeBerardinis RJ, Lum JJ, Hatzivassiliou G and Thompson CB: The biology of cancer: Metabolic reprogramming fuels cell growth and proliferation. Cell Metab 7: 11-20, 2008.

36. Warburg O: On the origin of cancer cells. Science 123: 309-314, 1956.

37. Samudio I, Harmancey R, Fiegl M, Kantarjian H, Konopleva M, Korchin B, Kaluarachchi K, Bornmann W, Duvvuri S, Taegtmeyer H, et al: Pharmacologic inhibition of fatty acid oxidation sensitizes human leukemia cells to apoptosis induction. J Clin Invest 120: 142-156, 2010.
38. Vander Heiden MG, Cantley LC and Thompson CB: Understanding the Warburg effect: The metabolic requirements of cell proliferation. Science 324: 1029-1033, 2009.

39. Santos CR and Schulze A: Lipid metabolism in cancer. FEBS J 279: 2610-2623, 2012

40. Currie E, Schulze A, Zechner R, Walther TC and Farese RV Jr: Cellular fatty acid metabolism and cancer. Cell Metab 18: $153-161,2013$.

41. Nieman KM, Kenny HA, Penicka CV, Ladanyi A, Buell-Gutbrod R, Zillhardt MR, Romero IL, Carey MS, Mills GB, Hotamisligil GS, et al: Adipocytes promote ovarian cancer metastasis and provide energy for rapid tumor growth. Nat Med 17: 1498-1503,2011.

42. Ramsay RR, Gandour RD and van der Leij FR: Molecular enzymology of carnitine transfer and transport. Biochim Biophys Acta 1546: 21-43, 2001

43. van Vlies N, Ferdinandusse S, Turkenburg M, Wanders RJ and Vaz FM: PPAR alpha-activation results in enhanced carnitine biosynthesis and OCTN2-mediated hepatic carnitine accumulation. Biochim Biophys Acta 1767: 1134-1142, 2007.

44. Brandt JM, Djouadi F and Kelly DP: Fatty acids activate transcription of the muscle carnitine palmitoyltransferase I gene in cardiac myocytes via the peroxisome proliferator-activated receptor alpha. J Biol Chem 273: 23786-23792, 1998.

45. Sharma S, Sun X, Rafikov R, Kumar S, Hou Y, Oishi PE, Datar SA, Raff G, Fineman JR and Black SM: PPAR- $\gamma$ regulates carnitine homeostasis and mitochondrial function in a lamb model of increased pulmonary blood flow. PLoS One 7: e41555, 2012.

46. Hou Y, Gao J, Xu H, Xu Y, Zhang Z, Xu Q and Zhang C: PPAR E3 ubiquitin ligase regulates MUC1-C oncoprotein stability. Oncogene 33: 5619-5625, 2014

47. Schooneman MG, Vaz FM, Houten SM and Soeters MR: Acylcarnitines: Reflecting or inflicting insulin resistance? Diabetes 62: 1-8, 2013.

48. Zhao QH, Cao Y, Wang Y, Hu C, Hu A, Ruan L, Bo Q, Liu Q, Chen W, Tao F, et al: Plasma and tissue free amino acid profiles and their concentration correlation in patients with lung cancer. Asia Pac J Clin Nutr 23: 429-436, 2014

49. Shingyoji M, Iizasa T, Higashiyama M, Imamura F, Saruki N, Imaizumi A, Yamamoto $\mathrm{H}$, Daimon $\mathrm{T}$, Tochikubo $\mathrm{O}$, Mitsushima T, et al: The significance and robustness of a plasma free amino acid (PFAA) profile-based multiplex function for detecting lung cancer. BMC Cancer 13: 77, 2013.

50. Abumrad NN and Miller B: The physiologic and nutritional significance of plasma-free amino acid levels. JPEN J Parenter Enteral Nutr 7: 163-170, 1983.

51. Nunez MI, Behrens C, Woods DM, Lin H, Suraokar M, Kadara H, Hofstetter W, Kalhor N, Lee JJ, Franklin W, et al: High expression of folate receptor alpha in lung cancer correlates with adenocarcinoma histology and EGFR [corrected] mutation. J Thorac Oncol 7: 833-840, 2012.

52. Weitman SD, Weinberg AG, Coney LR, Zurawski VR, Jennings DS and Kamen BA: Cellular localization of the folate receptor: Potential role in drug toxicity and folate homeostasis. Cancer Res 52: 6708-6711, 1992.

53. Rijnboutt S, Jansen G, Posthuma G, Hynes JB, Schornagel JH and Strous GJ: Endocytosis of GPI-linked membrane folate receptor-alpha. J Cell Biol 132: 35-47, 1996.

54. Kamen BA and Smith AK: A review of folate receptor alpha cycling and 5-methyltetrahydrofolate accumulation with an emphasis on cell models in vitro. Adv Drug Deliver Rev 56: 1085-1097, 2004.

55. Zhao HY, Chen GY, Huang Y, Li XL, Feng JF, Shi MQ, Cheng Y, Ma LX, Zhang YP, Gu CP, et al: Erlotinib plus capecitabine as first-line treatment for older Chinese patients with advanced adenocarcinoma of the lung (C-TONG0807): An open-label, single arm, multicenter phase II study. Medicine (Baltimore) 94: e249, 2015 